\title{
Research on SMEs Financing Issues
}

\author{
Shi $\mathrm{Yi}^{1, *}$
}

\author{
${ }^{1}$ Nanjing Agricultural University \\ *Corresponding author. Email: 27118103@njau.edu.cn
}

\begin{abstract}
With the ongoing globalisation of the economy, the competitive situation in the international financial market is becoming increasingly severe and the room for survival of SMEs is severely compressed, so the study of their financing has become a subject of concern. In terms of the influence of SMEs on economic development, all countries attach particular importance to them. Since the 18th National Congress of the Communist Party of China, the government has been increasing its support for SMEs, reflecting the important role of SMEs in the financial market. This paper examines the prevalent financing difficulties of SMEs as an object. It begins with a brief introduction to the classification of financing, followed by an analysis of the problems of SME financing today and their causes. Finally, in view of the difficulties in SME financing, it proposes solutions to improve the current situation of SME financing difficulties and the outlook for SMEs in the economic era, taking into account the actual situation. This paper finds that the low creditworthiness of SMEs, inadequate national safeguards and policies and credit discrimination by financial institutions all contribute to the financing problems faced by SMEs. Therefore, this paper suggests reducing the cost of SME financing, optimising SME financing channels and improving the internal management system of SMEs to improve corporate creditworthiness in order to solve the SME financing problem and present the outlook of SMEs in the economic era.
\end{abstract}

Keywords: SMEs, Financing difficulties, Policy support, Financial institutions.

\section{INTRODUCTION}

SMEs occupy a very important position in the national economy. Since the introduction of the market economy, China's SMEs, from small to large and from weak to strong, have flourished along the way, playing a non-negligible role in stabilising growth, promoting employment and fostering technological innovation. By the end of 2018, the number of SMEs in China exceeded 30 million, contributing $60 \%$ of GDP and $50 \%$ of tax revenue, and solving nearly $80 \%$ of the labour force's employment. In terms of the impact of SMEs on economic development, various countries have attached particular importance to them. Since the 18th Party Congress, China has been providing increasing support to SMEs, which has not only improved the efficiency of business registration, but also fully stimulated the vitality of the market and reflected the important role of SMEs in the financial market. However, SMEs, the mainstay of the national economy, has encountered numerous obstacles in their development, especially in terms of financing. SMEs in China not only face the real problem of capital shortage, but also face some "special problems", such as credit discrimination, unfair credit evaluation, inadequate laws and regulations and other objective problems[1]. Therefore, based on the current situation of SME development, this paper analyses the problems and causes of SME financing, and proposes constructive suggestions from the perspectives of reducing financing costs, optimising financing channels and improving financing structures, in the hope of providing a reference for other SMEs experiencing financing difficulties, promoting the healthy development of SMEs, and thus providing sustainable momentum for the high-quality development of China's economy.

\section{CLASSIFICATION AND DESCRIPTION OF SME FINANCING}

SME financing can be divided into two categories according to the origin of the funds: endogenous financing and exogenous financing. 


\subsection{Endogenous Financing}

Endogenous financing refers to the process of capital accumulation through the company itself. Internal source financing mainly includes internal cash financing, inventory asset revitalisation financing, internal debt financing and internal equity financing. Internal cash financing, as one of the main sources of financing, is the cash flow naturally generated by the business activities of the company. Retained earnings, depreciation and taxes constitute the internal cash financing of an enterprise. Inventory asset revitalisation financing plays an important role: on the one hand, it promotes the flow of assets and on the other hand, it reduces idle assets. Internal debt financing is a way of obtaining funds from employees, management, shareholders and other stakeholders. Internal financing comes from own assets, which listed companies have a great deal of autonomy in using, and in comparison to external financing of the company, whether in the form of shares, bonds or other forms of financing, there are significant costs to be paid, such as brokerage fees, accountants' fees, lawyers' fees and so on. Secondly, the use of undistributed profits financing does not dilute the earnings per share and control of the original shareholders In fact, in developed countries, this financing method is generally used as the preferred financing mode for enterprises ${ }^{[2]}$.

\subsection{Exogenous Financing}

Exogenous financing refers to the enterprise through a certain way to raise funds from other economic entities outside the enterprise. With the increasing growth of enterprises, internal financing to obtain funds is insufficient, enterprises will generally turn to external sources of financing. Exogenous financing includes bank financing, private financing, trust financing and so on. In addition, commercial credit and financial leasing are also part of exogenous financing to a certain extent. In turn, exogenous financing can be divided into two types: direct financing and indirect financing.

Since the 1990s, because of the continuous development of the capital market, enterprises have had more options for financing, and many of them have started to adopt direct financing to obtain funds. Mainly because of the weakening of national macro-control policies, direct financing is a major way for enterprises to obtain long-term funding. As the majority of enterprises are still financed mainly by banks, the financing of SMEs, especially non-state-owned enterprises, is basically not possible through the listing of shares and bonds. Therefore, direct financing is not a suitable form of financing for SMEs in China.

\section{PROBLEMS IN SME FINANCING}

\subsection{The Threshold of Credit is too High}

For SMEs in China, the amount of bank loans they can obtain is usually low and not sufficient to meet their normal needs, while the lack of funds also leads to a lack of talents. The lack of talent makes it difficult for enterprises to specify a relatively reasonable financing method and amount of financing, which in turn exacerbates the contradiction of financing gap. As we know from the 2018 white paper on developing small businesses issued by the State Council, the financing gap for SMEs is around RMB 22 trillion, and no real solution to this problem has been found so far. At present, the proportion of bank loans among SMEs in China reaches $40 \%$, but the proportion of credit loans among them only accounts for $27 \%$ of bank loans, and most of them are still mortgages, accounting for $73 \%$ of the total bank loans. As a result, there is a serious gap in financing for SMEs in China.

\subsection{Financing Channels are too Narrow}

Due to the difficulty of financing SMEs in China's financial market and the fact that China's financial market mechanism is not yet perfect, most SMEs are financed through self-financing. In addition to self-financing, SMEs can also turn to external sources of financing. There are two types of external direct financing: issuance of shares and bonds, and external indirect financing: bank loans or private lending. The two methods of equity and bonds have relatively strict requirements on the duration of continuous operation and business performance, which many SMEs simply cannot meet, so basically few SMEs choose to issue equity and bonds for financing. In addition, it is not easy for SMEs to obtain bank loans, as they also need to meet certain conditions to obtain loans from banks, and banks are generally reluctant to provide loans to SMEs due to risk considerations.

\subsection{High Cost of Financing for SMEs}

The cost of financing refers to the interest that SMEs have to pay after obtaining funds from financial institutions. In the case of bank loans, large and medium-sized enterprises are more likely to obtain loans than SMEs, and SMEs have to pay more variable interest because banks value the ability to protect their own assets and the ability of SMEs to obtain benefits. When banks grant loans, it is easier for state-owned enterprises to obtain loans, mainly because the assets of state-owned enterprises are larger, and bank loans are less likely to have bad debts or bad debts. Secondly, in the process of loan approval by banks, once there is a 
mortgage, there is also the need to pay additional fees for guarantees and asset appraisals, and most SMEs need to take out mortgage loans, which, to a certain extent, increases the financing costs of SMEs. In addition, the process of bank loans is more complicated and the cycle is long. For some SMEs with financing needs in the short term, they will turn to this form of private lending. The private lending process is simple and quick, but the interest rate is higher than that of banks, and the lending cycle is shorter, which also leads to higher financing costs for SMEs.

\subsection{Poor Financing Structure}

The financing structure is the composition and proportional relationship of all the capital of the enterprise, not only the composition and proportion of long-term equity capital and long-term debt capital at the bottom right of the static statement of the balance sheet; it also shows the composition within the debt capital, the composition and proportion of long-term capital and short-term capital, the composition within the equity capital. Different financing methods and financing channels in the financing structure have different liquidity requirements, and the correct choice of financing structure plays a key role in the development and operation of the enterprise. China's SMEs currently have a much larger proportion of short-term liabilities than long-term liabilities, and the average value of the current ratio is too low, with liquidity risk well above a reasonable threshold.

\section{EXPLORATION OF THE CAUSES OF FINANCING PROBLEMS OF SMES}

\subsection{Low Creditworthiness Leads to Increased Difficulty in Obtaining Loans}

Small and medium-sized enterprises are still poorly conceptualized in terms of credit, because the construction of China's credit system as a whole is relatively less than perfect. The creditworthiness of SMEs is even more difficult to guarantee, as most SMEs have imperfect internal systems, poor management, and a relative lack of operational capacity, and are not accurate enough to judge market risk expectations, resulting in low credit ratings. Firstly, the core condition for lending institutions to determine whether to provide loans to enterprises is the scale of the enterprise's operations, but most SMEs are now in the early stages of development and are small in scale, so most SMEs are easily included in the ranks of low credit lending enterprises by lending banks ${ }^{[3]}$. Secondly, there is a lack of information disclosure system. Generally speaking, the larger a company's operations are, the higher the performance of the information available, the relationship between the two is positive. At present, however, SMEs do not have an information disclosure system in place, resulting in a very low level of information transparency, which can lead to false information being provided to these lending institutions. Therefore, lending banks giving loans to SMEs are unable to monitor the business, thus making it impossible to achieve a balance of information between lending banks and SMEs.

\subsection{Inadequate safeguards and regulations}

At present, the smooth development of SMEs relies mostly on the support and maintenance of policies and laws by the state, and the core factor in promoting the development of SMEs is capital. However, there is a huge lack of systems and policies to protect SMEs in China and no corresponding measures have been implemented. For example, private lending institutions lack adaptive management policies and relevant regulatory constraints, which can easily lead to market risks, and it is difficult for the relevant authorities to introduce appropriate policies to guide private lending due to its diverse forms and scattered scale ${ }^{[4]}$. At the same time, because there is still a certain lag in the disclosure of information on private financing, just as there is still room for improvement in the management system of some intermediary financing institutions in China, China has not yet issued more applicable management methods for small and medium-sized enterprise credit guarantee institutions, as well as the formulation of industry access rules, so the problem of industry management risks of such lending institutions still cannot be solved. At the same time, the quality of practitioners also needs to be improved due to the lack of entry barriers ${ }^{[5]}$

\subsection{Credit discrimination by financial institutions}

In order to reduce the risk factor, various financial institutions will set up a set of strict evaluation system in their actual business activities. Due to the uneven development of SMEs in China, there are many SMEs whose market competitiveness is quite weak. Therefore, it is difficult to provide banks with relatively complete financial reports. Moreover, due to the lack of corresponding corporate credit, enterprises are less risk-resistant and therefore such enterprises are hardly a target group for banks to lend to. China's financial sector has been reformed many times, but financial resources are still highly monopolised. By the end of 2018, there were 4,588 banking financial institutions in China, of which state-owned commercial and joint-stock banks accounted for a large proportion, while some of these financial institutions have conservative credit concepts 
and asymmetries in the incentive and constraint mechanisms for lending to SMEs, usually belittling SMEs and suffering from They are often discriminatory in their financing, unwilling to lend to SMEs, set unreasonable conditions in granting credit, or only open up short-term credit operations ${ }^{[6]}$. Some commercial banks also ignore the operational efficiency of enterprises when assessing their credit rating, limiting their assessment to the size of their operations and the nature of their ownership, resulting in many SMEs having low bank credit ratings and being unable to obtain loans.

\subsection{Inadequate Competitiveness or Financing System}

SMEs are generally very small in scale, with insufficient number of employees, and therefore the corresponding internal management system is not perfect and lacks market competitiveness ${ }^{[7]}$. Some enterprises are even uncompetitive due to outdated equipment and technology. As the internal management is more chaotic, the economic efficiency is therefore relatively low. Many SMEs have not set up a corporate system that meets the requirements of the times, and have an inadequate financing system with little supervision. As a result, traditional financial institutions are unable to judge the business conditions and future prospects of enterprises well based on the status of their financial statements and other circumstances, requiring them to spend more time to assess the financing of enterprises, which exacerbates the difficulty for SMEs to borrow from traditional financial institutions.

\section{RESPONSES TO THE FINANCING PROBLEMS OF SMES}

\subsection{Reduce the Cost of Financing for SMEs}

For SMEs, it is not right to either choose the same type of financing or to stick to a fixed number of financing methods. Excessive financing can change the capital structure of SMEs and make it difficult for them to move forward in the event of a crisis. Therefore, there should be an appropriate financing structure for different types and sizes of SMEs, or for different stages of development of the same SME. In improving the SME financing management system, it is necessary to make relevant assessments for different types and sizes or for different stages of development of the same type of SME according to the characteristics of Chinese SMEs, and to keep actively exploring new financing methods so as to obtain the best financing structure solutions, such as categorising and valuing loan collateral according to the different industries of SMEs, thus improving the valuation of collateral The value of the collateral. The State may also provide a limited guarantee for the collateral to reduce the cost of guarantee for SMEs, thus effectively reducing the cost of financing and improving the efficiency of financing.

The State has given preferential policies for bond financing to high-tech enterprises, and SMEs are high-tech enterprises that should reasonably explore and use bond financing. The advantages of bond financing are: the corporate income tax for general enterprises is $25 \%$, and high-tech enterprises enjoy a $15 \%$ after-tax discount on top of this. The cost of bond financing is lower than that of equity financing and short-term bank borrowing, and the reasonable integration of bond financing with other financing methods can reduce the total cost of financing. Bond financing does not fragment the shareholder control of the enterprise, and is conducive to increasing shareholder returns compared to equity financing ${ }^{[8]}$.

\subsection{Optimise SME Financing Channels}

Small and medium-sized enterprises can also break through the existing financing model and try innovative other financing methods. In the light of China's national conditions, the research results at home and abroad, and the development conditions of the enterprises themselves, they can also try foreign chattel financing, pawn financing and supply chain financing. Although these models have already been implemented in foreign countries, they are still new in China and have the potential for development. These models can, to a certain extent, reduce the difficulty of financing and increase the likelihood of successful project financing. Multi-channel participation in projects can improve the efficiency of the project. As a global Fortune 500 company, Wal-Mart has a solid operation and has clear payment deadlines for its upstream product suppliers. Banks can use Wal-Mart as a core enterprise and give a certain credit line to its upstream suppliers after a comprehensive assessment.

In today's era, with the rapid development of the Internet, crowdfunding financing has gained a lot of attention as a new type of financing. Crowdfunding is a way of raising funds from netizens through the Internet. Compared with traditional financing methods, crowdfunding financing has a low threshold and no restrictions on financing capital ${ }^{[9]}$. At the same time, financing channels can be developed by optimising the service process. SMEs with capital needs can seek interested investors and financiers by submitting their relevant information online. Financial leasing can also be adopted to increase the financing problems of SMEs. Leasing companies can alleviate the capital required by SMEs to purchase fixed assets and equipment by leasing them to them as a form of financing. There is also a 
need to make good use of the relevant functions of the government to address the asymmetries that arise in SME financing. Long-term financing cooperation mechanisms can also be established through the government acting as an intermediary, with banks docking with enterprises, financing investment and investment promotion. This is all through some indirect financing methods to optimise financing channels ${ }^{[10]}$.

\subsection{Sound Internal Management System of SMEs and Improve the Social Image of Enterprises}

SMEs should start from themselves, expand the scale of their business, focus on the cultivation of talents, and pay attention to the innovation ability of enterprises. Improve the internal core competitiveness of SMEs. Improve the internal management system of the enterprise, improve the efficiency of business activities and establish a modern enterprise management system in line with the market economy. It is also necessary to standardise the financial system of enterprises, focus on the quality training of financial and accounting personnel, strengthen the management of financial information and guarantee the authenticity of financial information. Enterprises need to deeply understand the importance of credit, strengthen their own credit construction, take integrity as the basis, and uphold the principle of honesty and trustworthiness in the business process. Enterprises should treat credit as part of their daily business management, accept social supervision, strengthen cooperation and communication with other financial institutions, pay back on time, not default on debts, not evade debts, and create good inherent conditions for enterprise financing.

\subsection{Improve Relevant Policies and Regulations}

At present, China's laws and regulations on the management of SME financing are not very perfect, especially at this time when Internet finance is booming, there is a great lack of relevant institutional protection. Therefore, this paper suggests that we should start to build the corresponding laws and regulations for SME financing. In addition, the government should also invest human and material resources to set up a third-party institution to supervise SME financing, for example, the state should introduce corresponding policies for private financing institutions, and while giving legalization, it should also strengthen supervision to guarantee the smooth and orderly development of the financing market ${ }^{[11]}$.

\section{CONCLUSION}

Although the scale of SMEs is small, they play an important role in China's national economy. In the process of their development, SMEs still face many problems, which are reflected in their financing. The problem is reflected in the difficulty of obtaining credit loans due to the poor credit system and the discrimination in the financial sector. At the same time, most SMEs are unable to meet the strict national requirements for issuing shares and bonds, resulting in considerable restrictions on their access to finance. In general, SMEs have a much higher cost of bank loans than larger companies due to their lower asset protection and risk resistance. The high cost of financing for SMEs in the current situation has directly led to higher costs for the company, and at the same time, in the face of huge pressures, has caused some negative effects on the capital chain of the company. Only through reasonable financing can the financial difficulties of SMEs be solved and further space for development be obtained. In this regard, the market should support SMEs to break through the traditional financing model and innovate diversified financing methods, such as guaranteeing collateral for intangible assets including patents and trademarks, expanding the scope of credit loans and improving the possibility of financing. Society, financial institutions and the enterprises themselves should also focus on the construction of the credit system and collaborate to establish a good social credit environment to provide prerequisites for the financing environment, so that SMEs can better comply with the development of the market economy and add to the development of the national economy.

\section{ACKNOWLEDGMENT}

First of all, I would like to extend my sincere gratitude to my supervisor Pro. Alexei Parakhonyak, for his instructive advice and useful suggestions on my thesis. I am deeply grateful for his help in the completion of this thesis.

High tribute shall be paid to Ms. Ma Wenqiu, whose profound knowledge of Finance triggers my love for this wonderful discipline and whose earnest attitude tells me how to conduct academic research.

I am also deeply indebted to Ms.Chen Ximing and all the other tutors and teachers for their direct and indirect help to me with my very first thesis.

Special thanks should go to my friends who have put considerable time and effort into their comments on the draft.

Finally, 1 am indebted to my parents for their continuous support and encouragement. 


\section{REFERENCES}

[1] China SME Yearbook Editorial Committee. China SME Yearbook ( 2015 ) [M].Beijing:Enterprise Management Publishing House, 2016:45-52.

[2] Liu Xiaolin. study on the financing difficulties of small and medium-sized enterprises [J]. Communication of Finance and Accounting,2010(1):13-14.

[3] Guo Xiaodong,Zhu Jie. Experiences and Insights from Domestic and Foreign Countries in Solving the Financing Difficulties of SMEs [J]. Inquiry into Economic Issues,2012(3):90-92.

[4] Lin Shuyue, Zhang Shaqi, Yang Fengsu. SME financing and informal finance in the post-financial crisis era [J]. Research of Finance and Accounting,2011(4):59-61.

[5] Miao Dalei. The development of private finance and the response to the financing dilemma of SMEs under the financial crisis [J]. Journal of Zhengzhou University(Philosophy and Social Sciences Edition),2010,43(5):79-82.

[6] Chen Jincui. Study on Financing of Small and Medium Enterprises in the Context of Economic Transformation [J]. Shanghai Finance,2012(2):113-114.

[7] Cui Hongjian,Liang Wan. Learning from foreign experience to solve Guangdong's SME financing problems [J]. Science and Technology Management Research,2010 (6): 51-53.

[8] Wu Xia,Qian Yubo. SME Financing: Cases and Practical Guidelines [M].Beijing:China Machine Press,2011(3):45-56.

[9] Song Yu. SME financing: realities and reflections [M]. Beijing:Economic Science Press, 2012(4):322-356.

[10] Tian Fen,Huang Dongshi,Qin Yanmei. Study on the financing system to support the development of SMEs $[\mathrm{M}]$. Beijing: Economic Science Press,2012(6):134-146.

[11] Lv Jinsong. Reflections on the problem of difficult and expensive financing for SMEs [J]. Journal of Financial Research,2015(11):115-123 